\section{Serious verapamil poisoning: treatment with intravenous calcium gluconate}

Verapamil is an antiarrhythmic and antianginal drug which selectively inhibits membrane transport and release of calcium from the endoplasmic reticulum, depressing the sinus node and atrioventricular conduction as well as producing a negative inotropic effect on the myocardium. Here I describe a patient who suffered the adverse haemodynamic and electrocardiographic effects consequent upon selfpoisoning with $3.2 \mathrm{~g}$ of verapamil and was successfully resuscitated by intravenous administration of calcium gluconate.

\section{Case Report}

A 19-year-old woman with a four-year history of ventricular extrasystoles associated with a prolapsing mitral valve swallowed eighty $40-\mathrm{mg}$ tablets of verapamil after a domestic argument. On admission and after gastric lavage she had a bradycardia of 55 and was hypotensive (blood pressure $80 / 60 \mathrm{~mm}$ $\mathrm{Hg}$ ). The ECG showed a nodal bradycardia with abnormal intraventricular conduction and prominent $U$ waves. Five hours after the tablets had been swallowed her hands and feet became cold and cyanosed and her systolic blood pressure fell to $60 \mathrm{~mm} \mathrm{Hg}$. In view of the history of arrhythmia, $\beta$ adrenergic agonists such as orciprenaline normally recommended for the treatment of verapamil poisoning were considered to be contraindicated. The patient was given a slow intravenous injection of calcium gluconate ( $10 \mathrm{ml}$ of $10 \%$ calcium gluconate) over five minutes with continuous electrocardiographic monitoring (figure). Initially the ECG showed periods of either nodal bradycardia with an intraventricular conduction defect or alternate sinus and nodal beats, but within 10 minutes sinus rhythm was restored. Blood pressure rose slowly to $90 / 60 \mathrm{~mm} \mathrm{Hg}$ and the signs of diminished peripheral perfusion receded.

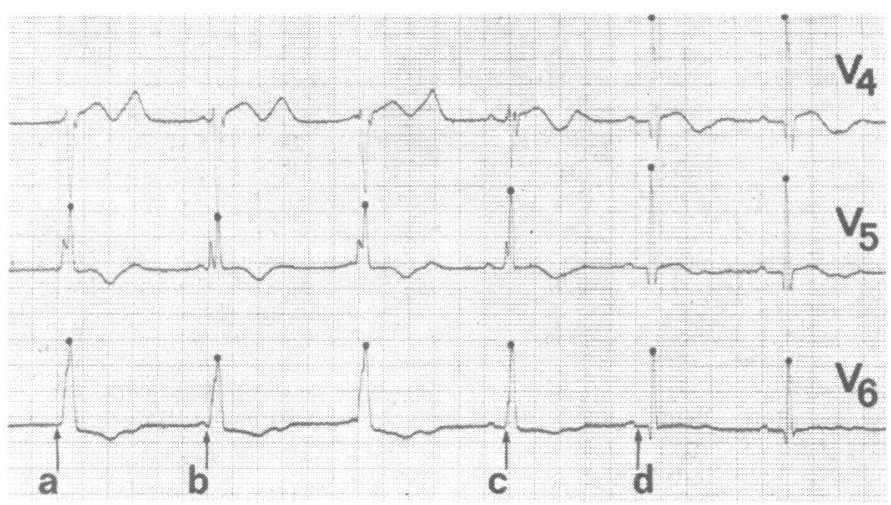

Simultaneous electrocardiographic recording of leads V4, V5, and V6 during a calcium gluconate infusion: (a) nodal beat with wide QRS and prominent $\mathrm{U}$ wave; $(b)$ return of atrial activity; (c) normal $\mathbf{P}$ wave and $\mathrm{P}-\mathrm{R}$ interval with wide QRS complex; $(d)$ return to normal electrocardiogram.

Sinus bradycardia persisted for eight hours and then reverted to a nodal bradycardia with an intraventricular conduction defect but without a fall in blood pressure. This arrhythmia responded temporarily to $10 \mathrm{ml}$ of $10 \%$ of calcium gluconate given intravenously but required a continuing infusion of calcium gluconate ( $5 \mathrm{mmol} / \mathrm{hour}$ ) to maintain sinus rhythm. Apart from an infrequent ventricular extrasystole the patient maintained sinus rhythm for 12 hours, at which point the calcium infusion was discontinued. Blood pressure was maintained at $100 / 60 \mathrm{~mm} \mathrm{Hg}$, although sinus bradycardia persisted for 36 hours after admission. The patient's further recovery was uneventful. The blood verapamil concentration was $4 \mu \mathrm{g} / \mathrm{ml}$ five hours after ingestion, compared with therapeutic concentrations of about $30 \mathrm{ng} / \mathrm{g}$ plasma.

\section{Comment}

The only published reports ${ }^{2}$ which describe the successful resuscitation of a patient after self-poisoning with verapamil do not give blood concentrations of the drug, nor was verapamil the sole agent responsible for the poisoning, having been ingested as Isoptin $S$ dragees (verapamil $40 \mathrm{mg}$ and pentobarbitone $20 \mathrm{mg}$ ); the synergistic cardiac depressant effect mediated by pentobarbitone, therefore, cannot be separately assessed. The maximum effect on atrioventricular conduction produced by oral verapamil in therapeutic doses occurs five hours after ingestion ${ }^{3}$; this would correlate well with the onset of hypotension and bradyarrhythmia seen in this patient.

Unlike $\beta$-blocking drugs verapamil does not alter myocardial responsiveness to $\beta$-adrenergic agonists. The manufacturer's recommended treatment of acute atrioventricular block or asystole precipitated by intravenous verapamil is an intravenous or intracardiac injection of orciprenaline or adrenaline followed by $10-20 \mathrm{ml}$ of a $10 \%$ calcium gluconate solution. In this case it is believed that return of normal cardiac function may be attributed to calcium gluconate alone. The use of $\beta$-adrenergic agonists may constitute a definite risk to a patient with previous episodes of arrhythmia or myocardial ischaemia.

Verapamil is being increasingly used in managing angina and certain arrhythmias, and the number of patients at risk from deliberate or accidental poisoning is likely to increase. An increasing incidence of poisoning has also been seen with other antiarrhythmic,agents such as disopyramide ${ }^{4}$ and beta-blockers. ${ }^{5}$ Knowledge of the physiological effects of these drugs and their potential antidotes, together with facilities for continuous electrocardiographic monitoring in an intensive care unit, should enable many patients to survive serious myocardial depression.

I thank Dr E B Mullock of Abbott Laboratories who performed the plasma verapamil assay, Miss S Tempest of the Poisons Information Centre at the Leeds General Infirmary, and Professor G P McNicol and Dr M R Lee for their help with the manuscript.

${ }^{1}$ Montiero, M L A, et al, Archives of Brazilian Cardiology, 1977, 30, suppl No. 2, p 401

2 Beitzke, A, et al, Pädiatrie und Pädologie, 1976, 11, 570.

3 Singh, B N, Drugs, 1978, 15, 178 .

Hayler, H, et al, Lancet, 1978, 1, 968.

5 British Medical fournal, 1978, 1, 1010.

(Accepted 1 August 1978)

University of Leeds Department of Medicine, Leeds General Infirmary, Leeds LS1 3EX

C M PERKINS, MRCP, teaching fellow in medicine

\section{Cerebrovascular accident after a "skipjack" reaction in a patient taking isoniazid}

Patients on anti-tuberculous chemotherapy have had reactions after eating "skipjack," a sea fish commonly consumed in Sri Lanka. ${ }^{2}$ The reactions-usually manifesting as headache, palpitations, erythema, redness of the eyes, itching, diarrhoea, and wheezing-are thought to be due to histamine absorbed in large quantities from the fish. Isoniazid, being a potent inhibitor of histaminase, interferes with the degradation of histamine, causing it to accumulate in the tissues. We report on a patient who, in addition to those transient symptoms, had a cerebrovascular accident after a skipjack meal.

\section{Case report}

A 50-year-old Indian labourer was admitted to hospital with pulmonary tuberculosis. He was treated with streptomycin $750 \mathrm{mg}$ intramuscularly each morning and Unithiben (thiacetazone $37.5 \mathrm{mg}$ and isoniazid $75 \mathrm{mg}$ ) four tablets every night. Two weeks after starting treatment the hospital lunch inadvertently included skipjack in a curry, which our patient and another ate against the advice of other patients who had experienced symptoms previously. Within 15 minutes both patients had reactions. Our patient developed flushing of the body, sweating, and giddiness. He went to bed. On waking about two hours later his left arm was paralysed and there was some stiffness of the left leg and numbness of the left half of the body. He had marked spastic weakness of the left arm, minimal weakness of the face, and mild weakness of hip flexion on the same side. The tendon jerks on the left were exaggerated and the plantar response was extensor. The cardiovascular system and the abdomen were clinically normal. The blood pressure about six hours after the onset of symptoms was $120 / 80 \mathrm{~mm} \mathrm{Hg}$.

The results of the following laboratory investigations were normal: white cell count and differential count, blood Wassermann reaction, blood sugar, serum $\mathrm{Na}^{+}$and $\mathrm{K}^{+}$, serum cholesterol, and urine analysis. The ESR was $40 \mathrm{~mm}$ in one hour. An ECG and radiographs of the skull were normal. 
No significant abnormality could be seen in an electroencephalograph about two weeks after the event, but a right carotid angiograph showed narrowing of a distal branch of the middle cerebral artery in the region of the trifurcation.

\section{Comment}

Acute hemiparesis with radiological findings of arterial narrowing suggest ischaemia in the right middle cerebral territory due to arterial occlusion. The fact that the hemiparesis occurred soon after the skip-jack reaction is significant. Skipjack contains a high concentration of histamine in the range of $390-900 \mathrm{mg} / 100 \mathrm{~g}$ tissue. ${ }^{1} \mathrm{An}$ other variety of fish, Scomberomorus, contains $0.5-7.5 \mathrm{mg} / 100 \mathrm{~g}$ tissue. Normally histamine absorbed from the intestine is readily metabolised in the tissues by two enzymes, n-methyl transferase and diamine oxidase (histaminase). But in the presence of isoniazid, a potent inhibitor of diamine oxidase, histamine absorbed from skipjack may reach toxic concentrations. These are thought to be the pharmacological basis of the "skipjack" reactions.

A major action of histamine in the human is capillary and arteriolar dilatation causing hypotension. Cerebral arterial occulusion may occur in predisposed individuals during acute hypotensive episodes, as in acute myocardial infarction and during anaesthesia. We think the sudden lowering of blood pressure due to histamine from the skipjack reaction precipitated the cerebral arterial occlusion in our patient. The well-known interaction between cheese and monoamine oxidase inhibitor through the mediation of tyramine has caused cerebrovascular accidents due to acute hypertension. Our case illustrates a similar food and drug interaction resulting in a cerebrovascular accident, but on this occasion probably due to acute hypotension.

${ }^{1}$ Kottegoda, S R, and Uragoda, C G, IRCS fournal of Medical Science, $1976,4,370$.

2 Uragoda, C G, and Kottegoda, S R, Tubercle, 1977, 58, 83.

(Accepted 9 August 1978)

General Hospital, Kandy, Sri Lanka

NIMAL SENANAYAKE, MD, MRCP, senior lecturer, university department of medicine

S VYRAVANATHAN, MB, TDD, medical officer in charge, chest clinic

$S$ KANAGASURIYAM, MB, house officer, tuberculosis ward

\section{Polymyalgia rheumatica and primary biliary cirrhosis}

Hepatic dysfunction is common in polymyalgia rheumatica $(\mathrm{PMR})^{1}$ but only one case of PMR with primary biliary cirrhosis (PBC) is recorded. ${ }^{2}$ We report three patients with PMR and features of PBC.

\section{Case reports}

(1) A 61-year-old woman presented with an exacerbation of chronic lumbago, tiredness, and morning stiffness lasting two hours. She had had recurrent shoulder and neck pains. Examination showed thoracic scoliosis with lumbar lordosis and pronounced tenderness of girdle musculature. The erythrocyte sedimentation rate (ESR) was $66 \mathrm{~mm}$ in $1 \mathrm{~h}$. Prednisolone $10 \mathrm{mg}$ daily relieved her rheumatism completely. The ESR fell to $28 \mathrm{~mm}$ in $1 \mathrm{~h}$. A raised serum alkaline phosphatase concentration (see table) led to hepatic investigations, which showed sharp fluctuations in serum enzymes and a titre of antimitochondrial antibody (AMA) rising to $1 / 1280$. She remains well three years later on $10 \mathrm{mg}$ of prednisolone daily.
(2) A 61-year-old woman developed mild diabetes mellitus when aged 51. Pruritis and a raised alkaline phosphatase level were noted. Two vears later investigation of haematuria revealed a stag-horn calculus, hypertension, and hepatosplenomegaly. Next year her diabetes required insulin. She also had urinary symptoms, hypochondrial pains, and lost weight. The ESR was $115 \mathrm{~mm}$ in $1 \mathrm{~h}$ and the alkaline phosphatase concentration had risen. A pyonephrotic kidney was removed and her diabetes remitted. When aged 56 she developed pain in the buttocks and shoulders. Shoulder movements were limited. She had splenomegaly and xanthelasma. PMR was suspected. She responded promptly to prednisolone $10 \mathrm{mg}$ daily. Needle biopsy of the liver some months later showed a multilobular cirrhosis, with heavy infiltration of the portal tracts with chronic inflammatory cells, and an absence of bile thrombi. Absence of bile nigment in the cells was consistent with corticosteroid therapy. ${ }^{3}$ Her ESR always exceeded $45 \mathrm{~mm}$ in $1 \mathrm{~h}$ and the serum alkaline phosphatase was over $800 \mathrm{IU} / \mathrm{l}$. The serum gamma-glutamyl transpeptidase concentration was $650 \mathrm{IU} / 1$ and the bilirubin was raised for the first time at $35 \mu \mathrm{mol} / 1(2.0 \mathrm{mg} / 100 \mathrm{ml})$. The prednisolone was tailed of without relapse of her PMR. She remained emaciated and pigmented and died from cerebellar haemorrhage.

(3) A 70-year-old woman had taken amylobarbitone for eight years. She lived in an arm chair and drank two pints $(1 \cdot 141)$ of milk daily. Her daughters noted depression, weight loss of four stone $(25.4 \mathrm{~kg})$ in two years, and increasing spinal curvature. She complained of hip and shoulder pains and stiffness lasting all day but worse in the mornings. She was thin, pigmented, had pronounced thoracic kyphosis, much pain on movement, and a waddling gait. Shoulder movements were limited and the hip muscles were tender. The ESR was $110 \mathrm{~mm}$ in $1 \mathrm{~h}$. Her symptoms responded partially to indomethacin. On prednisolone $10 \mathrm{mg}$ daily she became ambulant and could dress. Steatorrhoea and osteomalacia were found. Her blood vitamin D concentration was less than $0.8 \mu \mathrm{g} / 1$ (lower limit of normal $3.5 \mu \mathrm{g} / 1$ ), and serum calcium was $1.9 \mathrm{mmol} / 1(7.6 \mathrm{mg} / 100 \mathrm{ml}$ ) (albumin $32 \mathrm{~g} / \mathrm{l})$. Vitamin D and calcium were added to her diet and she began to eat and maintain weight. Four weeks later she died at home.

\section{Comment}

PMR is common and underdiagnosed. ${ }^{4}$ It is a clinical entity but not a true disease. Neoplasia and rheumatoid arthritis must be excluded. Painful, disabling, and demoralising, it responds well to corticosteroids. Temporal arteritis, which may occur in $5-50 \%$ of cases, was not found in our series. None of our patients took drugs known to induce PBC. Although PMR and PBC could coexist by chance, we believe they were related in our patients. That so few patients with both conditions have been described is surprising.* Perhaps the wider availability of mitochondrial antibody assay, although not invariably positive, ${ }^{5}$ might lead to the detection of more cases.

${ }^{1}$ Knorring, J, and Wasastjerna, C, Scandinavian fournal of Rheumatology 1976, 5, 197.

2 Walker, J G, Doniach, D, and Doniach, I, Quarterly fournal of Medicine $1970,153,31$.

${ }^{3}$ Kosolcharoen, P, and Magnin, G E, fournal of Rheumatology, 1976, 3, 50

${ }^{4}$ Coomes, E N, Ellis, R M, and Kay, A G, Rheumatology and Rehabilitation $1976,15,270$.

5 Doniach, D, and Walker, G J, Gut, 1974, 15, 664.

(Accepted 12 September 1978)

* Since the completion of this report Dr T J Hamblin, of the Department of Immunology, Royal Victoria Hospital, Bournemouth, has informed us of his study of 146 patients with antimitochondrial antibodies. In nine of these patients polymyalgia rheumatica had been diagnosed, and a further 26 had vague "rheumaticky" symptoms, for which diagnosis was uncertain. Thi series will be reported in detail later.

\section{Salisbury General Infirmary, Salisbury SP2 7SX}

J C ROBERTSON, MB, MRCP, consultant in rheumatology and rehabilitation G F BATSTONE, MB, MRCPATH, consultant chemical pathologist

Barnet General Hospital

W Y LOEBL, MD, MRCP, consultant rheumatologist

.

